cơ tim không ST chênh lên, hệ số tương quan $(r=-0,495 ; p<0,05)[9]$.

Mặc dù các yếu tố nguy cơ chính đã được xác định đối với xơ vữa động mạch, bao gồm tăng huyết áp (HTN), tăng lipid máu, đái tháo đường (DM), hút thuốc lá, v.v., là căn nguyên của bệnh động mạch vành. Tuy nhiên, ngày càng có nhiều bằng chứng từ các nghiên cứu cho thấy có nhiều yếu tố khác nữa cũng là nguy cơ của bênh mach vành, trong đó có nồng độ bilirubin toàn phần huyết tương. Nồng độ bilirubin huyết tương cao hơn có liên quan đến khả năng chống lai thiếu máu cục bộ cơ tim ở những bênh nhân bị tắc mạch vành toàn bộ mãn tính [1].

\section{KẾT LUÂN}

Nồng độ Bilirubin toàn phần trong huyết tương thấp có liên quan đến mức độ tổn thương nặng động mạch vành (hẹp $\geq 50 \%$ và theo điểm Gensini); có mối liên quan nghịch khá chặt với mức độ tổn thương động mạch vành được tính theo thang điểm Gensini $(r=-0,52, p<0,001)$.

KIẾN NGHI. Nên làm xét nghiệm Bilirubin toàn phần thương quy ở bệnh nhẩn có bệnh động mạch vành để có thêm yếu tố tiên lượng mức độ tổn thương động mạch vành.

LờI CẢM ON. Xin trân trọng cảm ơn Ban Giám Đốc, Hội đồng Khoa học, Khoa Tim mạch, Bộ môn Sinh hóa và các đồng nghiệp tại Bệnh viện Trung ương Thái Nguyên đã giúp chúng tôi hoàn thành nghiên cứu này.

\section{TÀI LIÊU THAM KHẢO}

1. Khalil T. S., Ibrahim W. A., Elmalla M. A. A. (2019), Serum Bilirubin as a Predictor of Coronary Artery Disease Severity in Patients
Undergoing Primary Percutaneous Coronary Intervention, World Journal of Cardiovascular Diseases, 9, 309-323.

2. Gensini G.Goffredo (1983), "A more meaningful scoring system for determining the severity of coronary heart disease", The American Journal Cardiology, 51(3), pp. 606.

3. Rostami R, Mahdi Najafi M, Sarami R, et al (2017) "Gensini scores and well-being states among patients with coronary artery disease", ARYA Atheroscler,13(5):205-210.

4. Hoàng Công Tùng (2018), "Nồng đô aolipoprotein $b$ huyết tương ở bệnh nhân mắc bênh tim thiếu máu cực bô điều trị tại Bênh viên Trung ương Thái Nguyên", Luân văn thạc sỹ y hoc, Trường Đại học Y Dược Thái Nguyên.

5. Pham Manh Hùng, Pham Nhât Minh, Horn Sophea, Nguyến Hoàng Khánh (2016), "Tìm hiếu mối liên quan giữa hàm lương bilirubin toàn phân trong huyết tương và mức độ tổn thương động mạch vành", Tạp chí Tim mạch học Việt Nam, số 77, p.42-49.

6. Nguyển Phương Anh, Phạm Mạnh Hùng (2010), Nghiên cứu vai trò của siêu âm trong lòng mạch (ivus) trong đánh giá tổn thương hẹp động mạch vành mức độ vừa, Tạp chí Tim mạch học Viêtt Nam, Số 53, p. 68-78.

7. Leem J , Eun Hee Koh, Jung Eun Jang et al (2015), Serum Total Bilirubin Levels Provide Additive Risk Information over the Framingham Risk Score for Identifying Asymptomatic Diabetic Patients at Higher Risk for Coronary Artery Stenosis, Diabetes Metab J;39:414-423

8. Akboga, M.K., et al., Association of serum total Bilirubin level with severity of coronary atherosclerosis is linked to systemic inflammation. Atherosclerosis, 2015. 240(1): p. 110-4

9. Şahin, Ö., et al., Relation between Serum Total Bilirubin Levels and Severity of Coronary Artery Disease in Patients with Non ST Elevation Myocardial Infarction. Journal of the American College of Cardiology, 2013. 62(18_S2): p. C217-C218.

\title{
KHẢO SÁT Độ DÀI Cổ TỬ CUNG Ở 3500 THAI PHU CÓ TUỔI THAI TỪ 19-23 TUẦ 6 NGÀY BẰNG SIÊU ÂM QUA ĐƯỜNG ÂM ĐẠO
}

\author{
Vũ Bá Quyết*, Nguyễn Xuân Hợi*, Đào Thị Hoa*, \\ Đinh Bích Thủy*, Nguyễn Thị Huyền Linh*
}

\section{TÓM TẮT.}

Mục tiêu: Khảo sát độ dài cổ tử cung (CTC) ở 3500 thai phu có tuổi thai từ 19- 23 tuân bằng siêu âm qua đường âm đạo. Đối tượng và phương pháp

*Bệnh viện Phụ Sản Trung ương Chịu trách nhiệm chính: Vũ Bá Quyết Email: Quyetvb2000@yahoo.com Ngày nhận bài: 18.01.2021

Ngày phản biên khoa họ: 12.3 .2021 Ngày duyệt bài: 22.3.2021 nghiên cứu: nghiên cứu mô tả cắt ngang, 3500 thai phu đến khám thai tại Khoa Khám bênh - BVPSTW có tuổi thai từ $19-23$ tuần phù hợp với tiêu chuẩn lựa chon và tiêu chuẩn loai trừ. Các thai phu được khám lâm sàng, siêu âm hình thái thi nhi và đo độ dài cổ tử cung trong khoảng thời gian từ tháng 02/2019 đến tháng 03/2021. Kết quả nghiên cứu: Độ dài CTC trung bình của 3500 thai phụ có tuổi thai từ 19-23 tuần là $35,8 \pm 5,5 \mathrm{~mm}$, không có sư khác biêt về độ dài CTC trung bình giữa các tuần thai. Độ dài CTC trung bình ở nhóm đẻ đủ tháng là $36,5 \pm 5,7 \mathrm{~mm}$, độ dài CTC trung bình ở nhóm có tiền sử đẻ non là $35,2 \pm 6,3$ mm; 
sự khác biệt về độ dài CTC trung bình giữa hai nhóm có ý nghĩa thống kê với $P<0,05$. Nhóm có độ dài CTC ngắn $(\leq 25 \mathrm{~mm})$ có nguy đẻ non cao gấp 4 lần so với nhóm có độ dài CTC bình thường $(\mathrm{OR}=4 ; 95 \% \mathrm{CI}: 2,2-$ $7,6)$. Tỷ lệ thai phụ có độ dài CTC ngắn $(\leq 25 \mathrm{~mm})$ trong nghiền cứu là $1,9 \%$ (65 trường hợp). Kết luận:

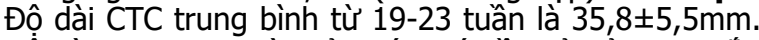
Đổ dài CTC trung bình ở nhóm có tiền sử đẻ non ngắn hớn có ý nghĩa thống kê so với nhóm đẻ đủ tháng. Tỷ lệ thai phu có đô dài CTC $\leq 25 \mathrm{~mm}$ là $1,9 \%$.

Tư khóa: Đẻ non, Độ dài CTC, Siêu âm qua đường âm đạo.

\section{SUMMARY \\ EVALUATION OF THE CERVICAL LENGTH AT 19-23 WEEK 6 DAY'S GESTATION IN 3500 PREGNANCIES BY TRANSVAGINAL ULTRASOUND}

Objective: Evaluation of thecervical lengthin 3500pregnancies at 19-23-week 6 day $^{\prime}$ gestationbytransvaginal ultrasound. Subject and methods: A descriptive cross-sectional study involved 3500pregnancies at 19-23week 6 day' gestation meeting the inclusive and exclusive criteria was implemented at Outpatient Department of National Hospital of Obstetrics and Gynecology (NHOG) from $02 / 2019$ to 03/2021. Participants were clinically examined, underwent fetal ultrasound examination, and the cervical length was measured and collected. Results: The mean of cervical length of 3500 participants at $19-23$ week 6 day' gestation was $35,8 \pm 5,5 \mathrm{~mm}$, with nosignificant difference among weeks. In the previousterm birth group, the mean of cervical length was $36,5 \pm 5,7 \mathrm{~mm}$, while in the group with previous preterm birth, the datum was $35,2 \pm 6,3$ $\mathrm{mm}$. This difference was statistically significant with $P<0,05$. The risk of preterm birth in the group with cervical length $\leq 25 \mathrm{~mm}$ was 4 times higher than that in the normal group $(\mathrm{OR}=4 ; 95 \% \mathrm{CI}: 2,2-7,6)$. The ratio of participants with short cervical length amounted to $1,9 \%$ (65 people). Conclusion: The mean of cervical length at 19-23week' gestation was $35,8 \pm 5,5 \mathrm{mmThe}$ cervical length in group with previous preterm birth was shorter than that in the term birth group with a statistically significant difference. The amount of cervical length $\leq 25 \mathrm{~mm}$ accounted for $1,9 \%$.

Key words: Preterm birth, Cervical length, Transvaginal ultrasound.

\section{I. ĐẶT VẤN ĐỀ}

Đẻ non được định nghĩa là tình trạng trẻ được sinh ra trước 37 tuần của thai kỳ. Theo tổ chức $Y$ tế thế giới (WHO), tỷ lệ đẻ non trên toàn thế giới dao động trong khoảng từ $5-18 \%[1]$. Ước tính mỗi năm có khoảng 15 triệu trẻ đẻ non được sinh ra vàgần 1triệu trẻ em tử vongdo các biến chứng của đẻ non[2].

Độ dài CTC luôn là một triệu chứng thực thể, phản ánh sự co ngắn của CTC dưới tác dụng của những cơn co tử cung không mong muốn. Độ dài CTC ngắn đã được chứng minh là có liên quan tới sự gia tăng của nguy cơ đẻ non.Vì vậy xác định được những sản phụ có độ dài CTC ngắn cho phép bác sĩ sản khoa cơ hội phát hiện và điều trị dự phòng để giảm nguy cớ đẻ non[3].

Có nhiều phương pháp siêu âm đo độ dài CTC trong thai kỳ như siêu âm qua đường bụng, đường tầng sinh môn và đường âm đạo. Trong đó siêu âm đo độ dài CTC qua đường âm đạo được đánh giá là một công cụ sàng lọc có hiểu quả cao và là tiêu chuẩn vàng để xác định độ dài CTC [4]. Chính vì vậy, chúng tôi thực hiện nghiên cứu này với mục tiều: Khảo sát độ dài cổ tử cung ơ 3500 thai phụ có tuôi thai từ 19 - 23 tuần bằng phương pháp siêu âm qua đường âm đạo.

\section{II. ĐỐI TƯỢNG VÀ PHƯƠNG PHÁP NGHIÊN CỨU}

2.1. Đối tượng nghiên cứu. 3500 thai phụ có tuổi thai từ $19-23$ tuần 6 ngày đến khám thai tại Khoa Khám bệnh - BVPSTW. Các thai phụ này được khám lẩm sàng, tư vấn, đồng ý tham gia nghiên cứu và được siêu âm hình thái, đo độ dài CTC. Thu thập kết quả siêu âm hình thái và độ dài CTC trong khoảng thời gian từ tháng 02/2019 đến tháng 03/2021.

\subsubsection{Tiêu chuẩn lứa chọn}

- Tuổi từ 19 - 55 tuối

- Số lượng thai: đơn thai

- Tuổi thai từ 19 - 23 tuần

- Thai đang phát triển bình thường

\subsubsection{Tiêu chuấn loại trừ}

- Thai bệnh lý, bất thường hình thái

- Có tình trang dọa sảy, thai đang sảy

- Dọa đẻ non, chuyển dạ đẻ non

- Tiền sử phấu thuật vùng CTC

- Các bệnh lý của tử cung: tử cung đôi,tử cung 2 sừng....

- Rỉ ối, OVN, rau bong non

- Mẹ có tình trạng bệnh lý: tim mạch, suy thận, hen, tiền sản giật....

- Thai phụ đang được điều trị Progesteron

\subsection{Phương pháp nghiên cứu}

2.2.1. Thiết kế nghiên cứu. Nghiên cứu mô tả cắt ngang

2.2.2. Cỡ mẫu nghiên cứu

$$
\mathrm{n}=\mathrm{Z}^{2}(1-\mathrm{a} / 2) \cdot \frac{\mathrm{p} \cdot \mathrm{q}}{(\mathrm{p} \cdot \varepsilon)^{2}}
$$

Trong đó n: số đối tượng nghiên cứu. a: mức ý nghĩa thống kê (chọn $a=0,05$ ).

$Z$ : hệ số tin cậy. $Z^{2}(1-$ a/2): giá trị $Z=1,96$ tương ứng với $a=0,05$.

$\varepsilon$ : giá trị tương đối, chọn $\varepsilon=0,19 . p=0,1$ theo Fonseca năm 2007, tỷ lệ thai phụ có độ dài CTC ngắn là $10 \%[5]$. 
Thay vào công thức ta có $\mathrm{n}=3457$. Chúng tôi đã lựa chọn được 3500 thai phụ đủ tiêu chuẩn nghiên cứu trong khoảng thời gian từ tháng 02/2019 đến tháng 03/2021.

2.2.3. Các biến số nghiên cứu. Thu thâp các thông tin sử dụng trong nghiên cứu qua mầu thu thập số liệu nghiên cứu bao gồm: tuổi thai phụ, tuổi thai đo độ dài CTC, kết quả độ dài CTC, tiền sử sản khoa.

2.2.4. Quản lý và phân tích số liệu. Sử dụng phần mềm SPSS 20.0 để quản lý và phân tích số liệu.

\section{KẾT QUẢ NGHIÊN CỨU}

Trong thời gian nghiên cứu từ tháng 02/2019 đến tháng 03/2021 chúng tôi thu nhận được 3500 thai phụ đến khám thai tại Khoa Khám bệnhcó tuổi thai 19 tuần đến 23 tuần. Tuổi trung bình của thai phụ là 29,3 tuổi (từ 19- 55 tuổi). Tuổi thai trung bình là 21,4 tuần. 211 thai phụ (6\%) có tiền sử đẻ non.

Bảng 1. Một số đặc điểm của đôî tượng nghiên cứu

\begin{tabular}{|c|c|}
\hline Tuổi (năm) & $29,3 \pm 5,4$ \\
\hline Tuối thai trung bình (tuần) & $21,4 \pm 1,3$ \\
\hline BMI trước mang thai $\left(\mathrm{kg} / \mathrm{m}^{2}\right)$ & $22,2 \pm 2,4$ \\
\hline Con so $(\mathrm{n}, \%)$ & $1145(32,7 \%)$ \\
\hline Tiền sử đẻ non $(\mathrm{n}, \%)$ & $211(6 \%)$ \\
\hline
\end{tabular}

3.1. Kết quả độ dài CTC trung bình theo tuổi thai

Bảng 2. Độ dài CTC trung binh theo tuổi thai $(n=3500)$

\begin{tabular}{|c|c|c|c|c|c|}
\hline \\
\hline Tuổi thai & Số lượng & $\begin{array}{l}\text { Độ dài trung bình } \pm \text { độ } \\
\text { lệch chuẩn }(\mathrm{mm})\end{array}$ & $\operatorname{Min}(\mathbf{m m})$ & $\operatorname{Max}(\mathbf{m m})$ & $\mathbf{P}$ \\
\hline Tuần 19 & 513 & $35,5 \pm 5,5$ & 17 & 55 & \multirow{6}{*}{$>0,05$} \\
\hline Tuần 20 & 528 & $35,9 \pm 5,3$ & 10 & 52 & \\
\hline Tuần 21 & 848 & $35,9 \pm 5,4$ & 10 & 61,4 & \\
\hline Tuân 22 & 1048 & $36,1 \pm 5,7$ & 12 & 56,4 & \\
\hline Tuần 23 & 563 & $35,6 \pm 5,8$ & 10,7 & 53,8 & \\
\hline Tổng & 3500 & 35,8 & $5 \mathrm{~mm}$ & & \\
\hline
\end{tabular}

Nhận xét: Độ dài CTC trung bình của 3500 thai phụ có tuổi thai từ $19-23$ tuần là $35,8 \pm$ $5,5 \mathrm{~mm}$. Độ dài CTC ngắn nhất là $10 \mathrm{~mm}$, dài nhất là $61,4 \mathrm{~mm}$. Độ dài CTC trung bình giữa các tuần thai không có sự khác biệt với $P>0,05$.

\begin{tabular}{|c|c|c|c|}
\hline & $\begin{array}{l}\text { Số lượng } \\
\text { (n) }\end{array}$ & $\begin{array}{l}\text { dài CTC trung } \\
\text { bình }(\mathrm{mm})\end{array}$ & $\mathbf{P}$ \\
\hline \multicolumn{4}{|c|}{ Số lân đẻ } \\
\hline Con so & 1145 & $34,7 \pm 5,0$ & $\mathrm{P}<$ \\
\hline Con ra & 2355 & $36,4 \pm 5,7$ & 0,001 \\
\hline \multicolumn{4}{|c|}{ Tiền sử đẻ non } \\
\hline Có & 211 & $35,2 \pm 6,3$ & $P=$ \\
\hline Không & 2144 & $36,5 \pm 5,7$ & 0,002 \\
\hline
\end{tabular}

Nhận xét: Độ dài CTC trung bình ở những thai phụ con so là $34,7 \pm 5,0 \mathrm{~mm}$. Độ dài CTC ở những thai phụ con rạ là $36,4 \pm 5,7 \mathrm{~mm}$. Sự khác biệt độ dài CTC trung bình giữa 2 nhóm có ý nghĩa thống kê với $P<0,05$

Độ dài CTC trung bình ở nhóm thai phụ có tiền sử đẻ non là $35,2 \pm 6,3 \mathrm{~mm}$. Độ dài CTC trung bình ở nhóm không có tiền sử đẻ non là $36,5 \pm$ $5,7 \mathrm{~mm}$. Sự khác biệt về độdài CTC trung bình giữa hai nhóm có ý nghĩa thống kê với $\mathrm{P}<0,05$.

3.3. Mối quan hệ giữa độ dài CTC và tiên sử đẻ non

Bảng 4. Mối quan hệ giữa độ dài CTC và tiền sứ đẻ non

\begin{tabular}{|l|c|l|l|}
\hline $\begin{array}{l}\text { Dộ dài CTC } \\
\text { Tiên sứ } \\
\text { đẻ non }\end{array}$ & $\begin{array}{c}\text { Bình } \\
\text { thường }\end{array}$ & Ngắn & OR \\
\hline
\end{tabular}

\begin{tabular}{|c|c|c|c|}
\hline Có & 198 & 13 & $\mathrm{OR}=4$ \\
& $(5,8 \%)$ & $(20 \%)$ & $(95 \% \mathrm{CI}:$ \\
\cline { 1 - 3 } Không & 3237 & 52 & $2,2-7,6)$ \\
\hline Tống & $(94,2 \%)$ & $(80 \%)$ & $\mathbf{3 4 3 5}$ \\
\hline
\end{tabular}

Nhận xét: Trong nhóm có độ dài CTC ngắn $20 \%$ thai phụ có tiền sử đẻ non, đối với nhóm có độ dài CTC bình thường tỷ lệ này chỉ là $5,8 \%$. Kết quả nghiên cứu cho thây nhóm có độ dài CTC ngắn có nguy cơ đẻ non cao gấp 4 lần so với nhóm có độ dài CTC bình thường. Sự khác biệt này có ý nghĩa thống kê với khoảng tin cậy $95 \%$ CI:2,2-7,6.

3.4. Tỷ lệ thai phụ có độ dài CTC $\leq 25 \mathrm{~mm}$

Bảng 5. Tỷ lệ thai phụ có độ dài CTC $\leq$ $25 \mathrm{~mm}$

\begin{tabular}{|c|c|c|}
\hline Độ dài CTC & Số lượng (n) & Tỉ lệ (\%) \\
\hline$\leq 15 \mathrm{~mm}$ & 8 & 0,2 \\
\hline $15-25 \mathrm{~mm}$ & 57 & 1,7 \\
\hline$>25 \mathrm{~mm}$ & 3435 & 98,1 \\
\hline Tống & $\mathbf{3 5 0 0}$ & $\mathbf{1 0 0}$ \\
\hline
\end{tabular}

Nhận xét: Trong 3500 thai phụ có 3435 trường hợp có độ dài $\mathrm{CTC}>25 \mathrm{~mm}$. Tỷ lệ thai phụ có độ dài CTC ngắn $\leq 25 \mathrm{~mm}$ là 65 trường hợp chiếm tỷ lệ 1,9\%. Trong đó có 8 trường hợp có độ dài CTC $\leq 15 \mathrm{~mm}$. 


\section{BÀN LUÂ̂N}

Đẻ non hiện nay là một trong những thách thức lớn trong sản khoa hiện đại.Mặc dù y học bộ đã có nhiêu tiến đáng kể trong chăm sóc sức khỏe trẻ sơ sinh, tuy nhiên tỉ lệ trẻ đẻ non có xu hướng gia tăng trong những thập kỉ gần đây [6]. Theo số liệu của WHO tại 184 quốc gia và vùng lãnh thổ trên thế giới, tỷ lệ đẻ non dao động từ $5-18 \%[1]$. Tỷ lệ thai phụ có tiền sử đẻ non trong nghiên cứu của chúng tôi là $8 \%$.

Trong nghiên cứu của chúng tôi với 3500 thai phụ có tuổi thai từ 19-23 tuần, độ dài CTC trung bình là $35,8 \pm 5,5 \mathrm{~mm}$, trong đó không có sự khác biệt có ý nghĩa thống kê về độ dài CTC trung bình giữa các tuần thai trong quý 2 thai kỳ. Điều này phù hợp với khuyến cáo của Hiệp Hội Sản Phụ Khoa Thế Giới (FIGO)năm 2015, tất cả phụ nữ có thai từ $19-23$ tuần 6 ngày nên được siêu âm đo độ dài CTC qua đường âm đạo để phát hiện và điều trị dự phòng những trường hợp có độ dài CTC < 25mm[4].

So sánh với kết quả nghiên cứu năm 2009 của Nguyễn Công Định, độ dài CTC trung bình ở 160 thai phụ có tuổi thai từ 20-24 tuần là $39,891 \pm 4,1 \mathrm{~mm}$ cao hơn so với nghiên cứu của chúng tôi [8]. Sự khác biệt này là do Nguyễn Công Định thực hiện đo độ dài CTC qua đường bụng, thai phụ phải nhịn tiểu làm cho CTC dài ra một cách nhẩn tạo. Nghiên cứu của chúng tôi tiến hành đo qua đường âm đạo, thai phu được hướng dẫn đi tiểu sạch trước siêu âm nển hạn chế được nhược điểm này.

Nhiều nghiên cứu được công bốchứng minh rằng có sự khác biệt về độ dài CTC trong thai kỳ giữa phụ nữ Châu Á và phụ nữ phương Tây. Điều này có thể liên quan đến các yêu tố như chiều cao, trọng lượng cơ thể và chủng tộc [9]. Chúng tôi cũng nhận ra rằng, các dân tộc khác nhau trong cùng một chủng tộc cũng là một yếu tố ảnh hưởng đến độ dài CTC. Độ dài CTC trung bình tại quý 2 thai kỳ của phụ nữ Việt Nam trong nghiên cứu này lớn hơn so với một số nước khác trong khu vực Châu Á ở một số nghiên cứu.

Bảng 5. Môi liên quan giữa chủng tộc và độ dài CTC 3 tháng giữa thai kỳ

\begin{tabular}{|c|c|c|c|c|}
\hline Dân tộc & $\begin{array}{c}\text { Trung } \\
\text { Quốc } \\
(\mathrm{n}=462)\end{array}$ & $\begin{array}{c}\text { Malaysia } \\
(\mathrm{n}=246)\end{array}$ & $\begin{array}{c}\text { Singapore } \\
(\mathrm{n}=911)\end{array}$ & $\begin{array}{c}\text { Thái Lan } \\
(\mathrm{n}= \\
1027)\end{array}$ \\
\hline Độ dài & 32,2 & $31,3 \pm$ & $31,9 \pm$ & $41,0 \pm$ \\
CT(mm) & $\pm 7,7$ & 6,9 & 7,5 & 11,0 \\
\hline
\end{tabular}

Độ dài CTC được biết đến là một công cụ tiên đoán tốt dự báo nguy cơ đẻ non đặc biệt ở những thai phụ đã có tiền sử đẻ non trước đó. Tương tự như vậy, nghiên cứu của chúng tôi đã nhận ra sự khác biệt có ý nghĩa về độ dài CTC giữa nhóm có tiền sử đẻ đủ tháng và nhóm có tiền sử đẻ non trước đó. Độ dài CTC trung bình ở nhóm đẻ đủ tháng dài hơn có ý nghĩa thống kê so với nhóm có tiền sử đẻ non $(36,5 \pm 5,7 \mathrm{~mm}$ và $35,2 \pm 6,3 \mathrm{~mm}, \mathrm{P}=0,002)$. Kết quả này tương đồng với kết quả nghiên cứu của Carvalho cùng các cộng sự năm 2005 tiến hành trên 1958 thai phụ đơn thai có tuổi thai từ 21-24 tuần, độ dài CTC trung bình ở nhóm đẻ đủ tháng là 35,8 $\pm 7,9 \mathrm{~mm}$ và ở nhóm có tiền sử đẻ non là 30,1 $\pm 10,1 \mathrm{~mm}$ với $\mathrm{P}<0,05$.

So sánh với kết quả nghiên cứu gần đây của Serene Thain tiến hành trên 911 thai phụ tại Singapore có tuổi thai từ $18-22$ tuần cũng chỉ ra sự khác biệt về độ dài CTC giữa 2 nhóm đẻ đủ tháng và có tiền sử đẻ non lần lượt là: $32,0 \pm 7,5 \mathrm{~mm}$ và $29,2 \pm 8,9 \mathrm{~mm}$. Sự khác biệt này có ý nghĩa thống kê với $P<0,05$.

Đã có nhiều bằng chứng chỉ ra mối liên hệ nghịch đảo giữa độ dài CTC trong thời kỳ mang thai và tần suất chuyển dạ sinh non. Nguy cơ tương đối của sinh non, sảy thai tăng lên khi độ dài CTC giảm. Phân tích mối liên quan giữa độ dài CTC và tiền sử đẻ non, trong nhóm có độ dài CTC ngắn $(\leq 25 \mathrm{~mm}) 20 \%$ thai phụ có tiền sử đẻ non, trong nhóm có độ dài CTC bình thường tỉ lệ này chỉ là $5,8 \%$. Sự khác biệt này có ý nghĩa thống kê với $\mathrm{OR}=4 ; 95 \% \mathrm{CI}: 2,2-7,6$. Điều này nói lên rằng, những thai phụ có độ dài CTC ngắn có nguy cơ đẻ non cao gấp 4 lần những thai phụ có độ dài CTC bình thường. Kết quả này trong nghiên cứu cũng tương đồng so với kết quả nghiên cứu của S.Cho năm 2017, những thai phụ có độ dài CTC ngắn có nguy có đẻ non cao gấp 3,25 lần so với những thai phụ có độ dài $C T C$ bình thường ( $O R=$ 3.250; 95\% CI: $1.5-7.1 ; P=0,003)$, độ dài CTC có liên quan tỉ lệ nghịch với tần suất sinh non, ngay cả đôi với những thai phụ có tiền sử sản khoa khỏe mạnh như sinh đủ tháng, không có các can thiệp trên CTC trước đó...

Tỷ lệ thai phụ có cổ tử cung ngắn $(\leq 25 \mathrm{~mm})$ của người Việt Nam trong nghiên cứu của chúng tôi là 1,9\% tương ứng với 65 trường hợp, trong đó có 8 trường hợp có độ dài CTC $\leq 15 \mathrm{~mm}$. Con số này thấp hơn so với một số nước phương Tây. Nghiên cứu của Edgar Hernandez năm 2012, tỷ lệ thai phụ có độ dài CTC $\leq 25 \mathrm{~mm}$ là $9,5 \%$. Trong số 21 trường hợp xác định có độ dài CTC ngắn $(\leq 25 \mathrm{~mm})$ qua siêu âm đường âm đạo chỉ có 9 trường hợp được phát hiện qua siêu âm đường bụng. Một nghiên cứu khác được tiến hành tại Thái Lan bởi Kiattisak Kongwattanakul và các công sự năm 2016, tỷ lệ thai phụ có độ dài CTC 
ngắn được phát hiện qua siêu âm đường âm đạo chỉ là $3,3 \%$; thấp hơn so với nghiên cứu của chúng tôi. Tuy nhiên số lượng thai phụ trong nghiên cứu của Kiattisak K. chỉ là 307, thấp hơn nhiều so với nhiên cứu của chúng tôi.

\section{KẾT LUÂ̂N}

Độ dài CTC trung bình của thai phụ từ 19-23 tuần là $35,8 \pm 5,5 \mathrm{~mm}$. Không có sự khác biệt về độ dài CTC trung bình giữa các tuần thai.

Có sự khác biệt về độ dài CTC trung bình giữa 2 nhóm thai phụ đẻ đủ tháng và nhóm thai phu có tiền sử đẻ non. Độ dài CTC trung bình ở nhóm có tiền sử đẻ non ngắn hơn có ý nghĩa thống kê so với nhóm phụ đẻ đủ tháng. Những thai phụ có độ dài CTC ngắn có nguy cơ đẻ non cao gấp 4 lần so với nhóm có độ dài CTC bình thường (OR=4; 95\%CI: 2,2-7,6).

Tỷ lệ thai phụ có độ dài CTC ngắn $(\leq 25 \mathrm{~mm})$ trong nghiên cứu là 1,9\%. Tuy nhiên để có một con số chính xác hơn về tỉ lế thai phụ Viêt Nam có độ dài CTC ngắn, cần có những nghiên cứu có số lượng cỡ mâu lớn hơn.

\section{TÀI LIÊU THAM KHẢO}

1. WHO (2018), Preterm birth, www.who.int.

2. Liu L., Oza S., Hogan D., et al. (2016). Global, regional, and national causes of under- 5 mortality in 2000-15: an updated systematic analysis with implications for the Sustainable Development Goals. Lancet, 388(10063), 3027-3035.

3. Kenneth Lim and Joan M. Crane K.B. (2018). No. 257-Ultrasonographic Cervical Length Assessment in Predicting Preterm Birth in Singleton Pregnancies. Journal of Obstetrics and Gynaecology Canada, 40(2), 151-164.

4. Neoma Withanawasam S.T. (2019). The shortened cervix in pregnancy: Investigation and current management recommendations for primary caregivers. Australian Journal of General Practice, 48(3), 12-15.

5. Fonseca EB, Celik E, Parra $M$, Singh $M$, Nicolaides KH. (2007). Progesterone and the risk of preterm birth among women with a short cervix. The New England journal of medicine, 357(5), 462-9.

6. Blencowe H., Cousens S., Oestergaard M.Z., et al. (2012). National, regional, and worldwide estimates of preterm birth rates in the year 2010 with time trends since 1990 for selected countries: a systematic analysis and implications. Lancet, 379(9832), 2162-2172.

7. FIGO COMMITTEE REPORT (2015). Best practice in maternal-fetal medicine. International Journal of Gynecology and Obstetrics, 128, 80-82.

8. Nguyến Công Định (2009), Nghiên cứu đo độ dài cổ tử cung ở phụ nữ có thai 20 - 24 tuần bằng phương pháp siêu ầm tầng sinh môn, Luân văn Thạc sỹ Y học, Đại học Y Hà Nội.

9. Buck J.N., Orzechowski K.M., and Berghella V. (2017). Racial disparities in cervical length for prediction of preterm birth in a low risk population. The Journal of Maternal-Fetal \& Neonatal Medicine, 30(15), 1851-1854.

\section{ĐẶC ĐIỂM LÂM SÀNG, CÂ̂N LÂM SÀNG HộI CHỨNG CAI RƯợU NẶNG ĐIỀU TRI TẠI TRUNG TÂM CHỐNG ĐộC BỆNH VIỆN BẠCH MAI}

\section{TÓM TẮT}

Mục tiêu: Nhận xét đặc điểm lâm sàng, cận lâm sàng hô̂i chứng cai rượ năng. Đối tượng và phương pháp: Ṅghiên cứu mô tả trên 38 bệnh nhân có hội chứng cai rươu nặng với điểm CIWA-Är $\geq 20$ điều trị tại Trung tâm chống độc bệnh viện Bạch Mai từ 1/2018 đến tháng 7/2018. Kết quả: $100 \%$ gặp ở nam giới:

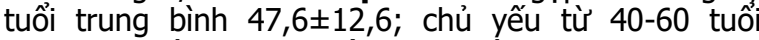
$(68,4 \%)$, thời gian nghiên rượu dài $18,7 \pm 8,55$ năm; uống $500-700 \mathrm{ml} / \mathrm{ngày}$ tới $63,2 \%$; hội chứng cai kéo dài trung bình 3,8 ngày. Đặc điểm lâm sàng: bệnh nhân có đầy đủ các dấu hiệu nặng theo thang điểm CIWA-Ar: dấu hiệu run (100\%), l̇o âu $(100 \%)$, vã mồ

${ }^{1}$ Trung Tâm Chông Độc, Bệnh viện Bạch Mai

2Trung tâm Cấp cứu, Bênh viện Bach Mai

Chịu trách nhiệm chính: Đặng Thị Xuân

Email: xuandangthi17@gmail.com

Ngày nhân bài: 12.01.2021

Ngày phản biên khoa hoc: 15.3.2021

Ngày duyệt bài: 23.3.2021

\section{Đặng Thị Xuân ${ }^{1}$, Đỗ Ngọc Sơn ${ }^{2}$}

hôi $(97,4 \%)$, kích động $(92,1 \%)$, buồn nôn và nôn $(28,9 \%)$, đau đâu $(15,8 \%)$. Các rối loạn ảo giác: thính giác $(92,1 \%)$, thị giác $(89,5 \%)$, xúc giác $(23,7 \%)$. Rối loạn định hướng ở $76,3 \%$ số bệnh nhân. Biến chứng viểm phổi $(39,5 \%)$ và $15,8 \%$ số BN phải thở máy. Đăc điểm cận lâm sàng: Tăng CK, AST, ALT, lactat. Kết luận: Hội chứng cai rượu nặng với nhiều triệu chứng và biến chứng, cần hồi sức và điều trị tại các đơn vị hồi sức tích cực.

Tư khóa: hội chứng cai, thang điểm CIWA-Ar.

\section{SUMMARY}

CLINICAL AND LABORATORY CHARACTERISTICS OF SEVERE ALCOHOL WITHDRAWAL SYNDROME

Objective: to assess clinical features and laboratory abnormalities of severe alcohol withdrawal syndrome. Subjects and Methods: An observational study on 38 patients with severe alcohol withdrawal syndrome (CIWA-Ar score $\geq 20$ ) treated at Poison Control Center of Bach Mai Hospital from January 